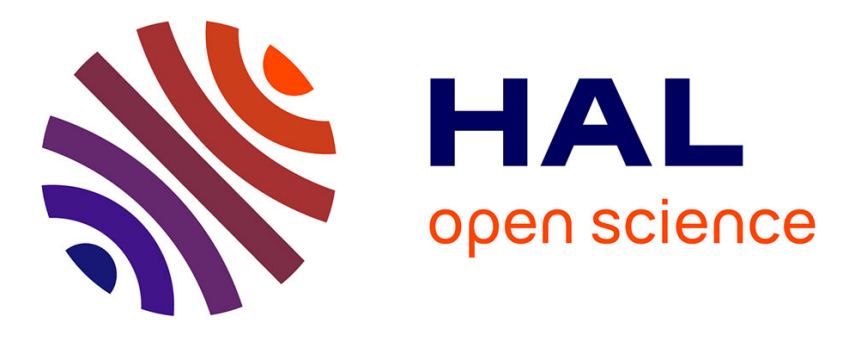

\title{
CFD modeling of riser with Group B particles
}

Sofia H. Rodrigues, Anne Forret, F Montjovet, M Lance, Thierry Gauthier

\section{To cite this version:}

Sofia H. Rodrigues, Anne Forret, F Montjovet, M Lance, Thierry Gauthier. CFD modeling of riser with Group B particles. Powder Technology, 2015, 283, pp.519-529. 10.1016/j.powtec.2015.05.020 . hal-01214338

\section{HAL Id: hal-01214338 \\ https://hal.science/hal-01214338}

Submitted on 12 Oct 2015

HAL is a multi-disciplinary open access archive for the deposit and dissemination of scientific research documents, whether they are published or not. The documents may come from teaching and research institutions in France or abroad, or from public or private research centers.
L'archive ouverte pluridisciplinaire HAL, est destinée au dépôt et à la diffusion de documents scientifiques de niveau recherche, publiés ou non, émanant des établissements d'enseignement et de recherche français ou étrangers, des laboratoires publics ou privés. 


\title{
CFD modeling of riser with Group B particles
}

\author{
Sofia S. Rodrigues $^{1 *}$, A. Forret ${ }^{1}$, F. Montjovet ${ }^{1}$, M.Lance ${ }^{2}$, Th. Gauthier ${ }^{1}$ \\ ${ }^{1}$ IFP Énergies Nouvelles, Rond-point de l'échangeur de Solaize, BP 3, 69360 Solaize, France \\ ${ }^{2}$ LMFA, École Centrale de Lyon, 36, avenue Guy de Collongue, 69134 Écully, France
}

\begin{abstract}
A series of tests were conducted in a large cold flow CFB unit (18 m long riser and $30 \mathrm{~cm}$ in diameter) with two different Group B powders. The impact of particle nature on the riser hydrodynamics was investigated at similar operating conditions through pressure taps and extraction probes. To study the impact of particle size and sphericity, sand and glass beads were used. Resulting axial pressure profiles are very different in both the acceleration and in the fully developed region. These differences can most probably be explained by the difference in shape between the solids. Higher sphericity seems to generate smaller pressure drop. Trough extraction probe measurements, the core-annulus regime was found on the developed zone of the riser. An assessment of a commercial CFD code to predict riser flow was carried out. For glass beads, simulation results agree reasonably well with experimental pressure profiles but the core annulus structure is underpredicted. However, pressure drop along the riser is strongly underestimated in sand simulations.
\end{abstract}

Keywords: CFB; riser; Geldart Group B; CFD; sphericity; hydrodynamics

\section{Introduction}

Chemical Looping Combustion (CLC) is an oxy-combustion like technology where oxygen carrying particles are used to supply oxygen for combustion [1-3]. The CLC process comprises two separate reactors, an Air Reactor and a Fuel Reactor. The oxygen carrier circulates between the Air Reactor, where it is oxidized in contact with air, and the Fuel Reactor, where it is reduced by burning fuels. $\mathrm{CO}_{2}$ can be easily recovered from the Fuel Reactor flue gases after steam condensation, since it is not diluted by $\mathrm{N}_{2}$. Based on energy penalty criteria, the CLC process is considered as one of the most promising routes for CCS (Carbon Capture and Storage).

The Air Reactor, as developed by IFPEN and Total, is a riser type reactor where the oxygen carrier, a metal oxide, is transported upwards by the air flow as it is being oxidized. In order to minimize the energy penalty of the CLC process, it is necessary to minimize pressure drop across the reactor while simultaneously achieving efficient oxidation of the oxygen carrier. This requires good control of contact time between air and oxygen carrier along the riser and therefore, an accurate knowledge of solid concentration as a function of operating conditions.

The oxygen carriers being considered for the CLC process are particles belonging to Group B of the Geldart classification. Indeed, these types of particles allow the use of non-mechanical valves (like the 
L-valve) that are employed for solids flow control at very high temperatures (around $900^{\circ} \mathrm{C}$ ) required for the CLC process [4]. In addition, Group B particles can be straightforwardly separated from unburned solid fuel at the Fuel Reactor exit based on size and density differences [5].

Most of the studies on riser hydrodynamic have been conducted with Group A powders, mostly for the FCC process [6,7]. However, Group B oxygen carrier particles are larger and heavier than FCC catalysts, which results in different overall flow behavior. There is a general lack of reliable modeling and experimental information in the literature on Circulating Fluidized Beds (CFBs) working with large materials. Furthermore, published work on Group B particles does not focus on the impact of particles shape $[8,9]$. Further studies are required for the reliable scale-up and optimization of the CLC process.

The broader goal of this study was, therefore, to gather basic experimental data on a circulating fluidized bed riser with different kinds of Group B particles closely related to CLC applications. The experimental results can then be used to improve understanding of gas-particle interactions and the real impact of particle properties such as size, density and sphericity, on riser flow. Experimental data, using three different Group B solids can be found on [10]. The development of a 1D model of the riser and the development of a new drag force correlation for Group B solids has been achieved [11].

In this paper, the principal results concerning sand and glass beads are recalled and results concerning local information are presented. Afterwards, simulation results by a commercial CFD code of the riser with Group B particles are discussed. The final objective of this study is to evaluate the ability of Barracuda to simulate the solid flow inside the riser and the impact of particle properties such as sphericity. Comparison of simulation results with experimental profiles allows the evaluation of the implemented drag law.

\section{Experimental set-up}

All experimental tests were conducted in a large scale cold flow circulating fluidized bed built at IFPEN Lyon. The cold flow mock-up is composed of two solid loops with a central riser, the primary loop being used for all stationary hydrodynamic tests. Besides the riser, both loops consist of a fluidized bed, a standpipe, an orifice valve, primary and secondary cyclones, and a filter as shown on Fig. 1.

The steel riser is $18 \mathrm{~m}$ high and has a $30 \mathrm{~cm}$ diameter. The riser is grounded and has a blind-T exit where slide valves can be inserted in each branch, in order to isolate one loop from another. Air is fed in the riser by a central jet with a diameter of $0.1 \mathrm{~m}$. Air relative humidity is controlled and kept constant at around $12 \%$. Gas velocity is determined from the values of the flowmeter feeding the riser. A fluidization ring, operating around 10.umf, is placed at the bottom of the riser. Particles are fed 0.5 $\mathrm{m}$ below the main gas inlet pipe to ensure symmetrical solid flow conditions downstream the riser. 
Several pressure taps, located along the riser, allow the measurement of axial pressure profiles. At 12 $\mathrm{m}$, extraction probes can be inserted in the riser for local solid flux measurements.

On the bottom of the standpipe, there is an interchanging orifice valve with aeration injections. The valve and aerations allow for the solid flux to be controlled. Solid mass fluxes are measured by a batch operation and are then correlated directly to riser pressure drop for a given gas flow rate. The batch operation consists on discharging the main fluidized bed of the CFB into the secondary fluidized bed through the riser and by recording bed level as a function of time. Correlations were developed for each solid and each gas velocity, to determine solid flux during normal operation from the continuously measured riser pressure drop. More information can be found in [10].

\subsection{Extraction probes}

Flux of solids can be measured inside the riser using extraction probes $[9,12,13]$. The probe tip, with an angle of $90^{\circ}$, is inserted in the riser either facing upwards or downwards to measure downflow or upflow of solids, respectively. Net flux is defined as the difference between the upflow and the downflow of solids. The extraction probes were operated at pseudo-isokinetic conditions, i.e., the vacuum velocity at the tip of the probe equals the superficial gas velocity in the riser [13-15].

The complete extraction system is shown on Fig. 2. Suction rate is controlled by a rotameter connected to the solids collection pot that sits on top of an electronic scale. The measurement duration is controlled with a standard stopwatch.

During the first extraction measurements, plugging issues were found for several experimental conditions. Plugging was detected all along the probe. These problems are not well documented on literate mostly because most studies focus on Group A particles, which are more easily transported. In an attempt to solve these issues, different designs of extraction probes were tested. The initial probe (probe (a) on Fig. 3) has an $8 \mathrm{~mm}$ inside diameter and a quite severe angle to place the probe tip perpendicular to the solids flow. The solids travel $14 \mathrm{~cm}$ vertically and 44 to $50 \mathrm{~cm}$ horizontally to reach the collection pot. The line connecting the extraction probe to the collection pot has the inside diameter of $8 \mathrm{~mm}$. A first attempt was made to solve the plugging issues a probe with a less abrupt angle, that would improve the solids passage (probe (b) on Fig. 3). This probe did not allow measurements to be made over the total riser diameter. However, the plugging problems persisted, which led to a probe (probe (c) on Fig. 3) with a smaller horizontal portion of $33 \mathrm{~cm}$. The last probe tested (probe (d) on Fig. 3) had a smaller horizontal portion and a wider entrance of 9,5 mm, but the same $8 \mathrm{~mm}$ inside diameter on the rest of the probe.

The last probe tested was the one that presented less plugging issues. Therefore, probe $\mathrm{d}$ was used for all the ensuing tests and the detailed geometry is represented on Fig. 4. This probe has a tip of $9.5 \mathrm{~mm}$ diameter, an inner diameter of $8 \mathrm{~mm}$, a vertical portion of $14 \mathrm{~cm}$ and a horizontal portion of $33 \mathrm{~cm}$. 


\subsection{Operating conditions and materials}

A wide range of operating conditions have been tested on the large scale CFB, but this paper will focus on two experimental conditions corresponding to potential operating conditions encountered in the air reactor of the CLC process in the following ranges: gas velocities of 8 and $10 \mathrm{~m} / \mathrm{s}$ and solid fluxes of about $55-60 \mathrm{~kg} / \mathrm{m}^{2} \mathrm{~s}$ Additional details and results can be found in [10].

The reported experimental tests were conducted with two different monodispersed Group B particles of the Geldart classification [16]: sand and glass beads. The different materials were chosen to study the impact of particle sphericity on riser flow. Microscopic images of sand and glass beads can be seen on Fig. 3 and Fig. 4, respectively. Particle properties for irregularly shaped sand and for spherical glass beads can be seen on Table 1. The mean diameter presented is the mean Sauter diameter calculated from several PSD measurements at experiments equilibrium state. Fig. 5 shows the particle size distribution (PSD) for the powders at equilibrium state. More detailed information can be found in[10].

The sphericity of a particle is defined as the ratio of the surface area of a sphere (with the same volume of the particle) to the surface area of the particle. Sphericity was determined experimentally through the method suggested by Kunii [1,17] and that uses the Ergun equation (see equation 14).

$$
\frac{\Delta \mathrm{P}}{\mathrm{h}}=150 \frac{\mu_{g} \cdot u_{g}}{\left(\phi \cdot d p^{2}\right)} \frac{(1-\varepsilon)^{2}}{\varepsilon^{3}}+1.75 \frac{\rho_{g} \cdot u_{g}^{2}}{\phi \cdot d p} \frac{(1-\varepsilon)}{\varepsilon^{3}}
$$

The value of sphericity is calculated through the fit of the Ergun equation to experimental points of pressure drop and voidage, at fixed gas velocity. These data points were obtained at a variety of gas velocities (inferior to the minimum fluidization velocity) by tapping the column between pressure drop measurements, to achieve different values of voidage.

As expected, sand particles and glass beads exhibit a large difference in particle sphericity (see Table 1). Based on literature, lower particle sphericity means higher drag force coefficient $[18,19]$. As shown in Table 1, terminal velocity of a single particle was calculated with the Haider \& Levenspiel [20] correlation, with $\left(\mathrm{u}_{t \phi}\right)$ and without $\left(\mathrm{u}_{\mathrm{t}}\right)$ particle shape correction.

\section{Results and discussion}

\subsection{Pressure profiles}

Solid hydrodynamic behavior inside the CFB riser was characterized through the measurement of axial pressure profiles. Profiles were obtained with the help of several pressure taps located along the riser at different experimental conditions for sand and glass beads [10]. A focus on the bottom $5 \mathrm{~m}$ of the riser was made to better characterize the acceleration region. Axial pressure profiles are shown on Fig. 6 for sand and glass beads at $8 \mathrm{~m} / \mathrm{s}$ and $55 \mathrm{~kg} / \mathrm{m}^{2} \mathrm{~s}$ and on Fig. 7 at $10 \mathrm{~m} / \mathrm{s} \& 60 \mathrm{~kg} / \mathrm{m}^{2} \mathrm{~s}$. Pressure at each elevation $\mathrm{H}$ is computed relative to the pressure at the riser gas inlet. Therefore, pressure 
profiles represent the difference between $\mathrm{P}_{0}-\mathrm{P}_{\mathrm{H}}$ as a function of height $\mathrm{H}$. The direct comparison between similar operating conditions aims at identifying the impact of sphericity on riser hydrodynamics.

The experimental axial pressure profiles exhibit the same trend, regardless of operating conditions. Therefore, the riser can be divided into three zones, according to pressure drop evolution. At the bottom of the riser, the nearly exponential increase of the pressure drop suggests the presence of a dense solid phase. In this region, particles are being accelerated by the inlet gas producing high pressure drop that can be as high as 50\% of the total riser pressure drop. For this reason, more data was collected on the first $5 \mathrm{~m}$ of the riser. Higher in the riser, in between 5 and $13 \mathrm{~m}$ approximately, pressure increases linearly with riser height. This evolution suggests that after a given height, particles will be fully accelerated and the flow becomes established. This nonlinear evolution of pressure in the riser is consistent with literature findings [9,21,22].

Finally, close to the riser exit (above $13 \mathrm{~m}$ ) pressure gradient increases due to the riser outlet configuration which decelerates particles. The blind-T pressure drop is not shown, but its impact is significant on the last two pressure points of the riser profile. Since velocities are moderate, the impact is also moderate. Pressure drop generated by the riser exit is dependent on the exit geometry [23,24]. Therefore, riser upper part results were not taken into account in further calculations.

As already described in [11], for identical operating conditions, sand pressure profiles are about twice as high as glass beads pressure profiles. This is a very large, significant and unexpected difference. Since density for sand and glass beads is almost identical, the results suggest a substantial impact of particle nature, i.e. diameter or sphericity, on riser hydrodynamics. Consequently, results imply that particle sphericity should be accounted for when studying solid flow inside the riser.

The development of a new cross section averaged drag force using the axial pressure profiles as a base to study the flow inside the riser has been made [10]. The developed drag force correlation applies to a 1D model. In this paper, the analysis of drag force expressions for multi-dimension starts. Because it is much more difficult to derive a multi-dimensional drag force than in $1 \mathrm{D}$, an evaluation of the performance of the existing drag force laws is first needed.

\subsection{Radial solid flux profiles}

Radial solid flux profiles were obtained for sand and glass beads at $12 \mathrm{~m}$ which corresponds to the developed region of the riser. Measurements were conducted along the riser radius at 12 different positions. In a few cases, profiles were conducted over the whole diameter. Results are not reported here but radial symmetry was found [10]. The measurements of solid flux were repeated at identical conditions and radial positions with the probe facing upwards and facing downwards. This method allows the measurement of upflow and downflow of solids in the vertical direction in the riser.

Fig. 10 shows the upflow and downflow radial solid flux profiles for sand at $60 \mathrm{~kg} / \mathrm{m}^{2} \mathrm{~s}$ and gas velocity of $10 \mathrm{~m} / \mathrm{s}$, where zero corresponds to the center of the riser and $0.15 \mathrm{~m}$ corresponds to the 
riser wall. It can be seen how the solid flow is not homogeneous over the riser diameter. The majority of solids upflow is made in the center of the riser. The flow of solids moving upwards decreases rapidly with the distance from the center. Close to the riser walls, there are solids moving downwards. This solid distribution suggests the presence of the core-annulus regime in the developed region of the riser. The core-annulus regime is well established in the literature as typical solid flow inside the riser $[14,25,26]$.

Glass beads radial net solid flux profile at $60 \mathrm{~kg} / \mathrm{m}^{2} \mathrm{~s}$ and gas velocity of $10 \mathrm{~m} / \mathrm{s}$ is shown on Fig. 11 . The net solid flux is obtained by subtracting the downward solid flux to the upward solid flux at each point. The core-annulus regime is found for glass beads in the developed region as well as for sand. High solid flux moves upwards in the center of the riser as a smaller amount of solids moves downwards at the riser walls. The same conclusion can be made from Fig. 12 of the radial net solid flux profile at $57 \mathrm{~kg} / \mathrm{m}^{2} \mathrm{~s}$ and gas velocity of $8 \mathrm{~m} / \mathrm{s}$. However, when comparing glass beads profiles at similar solid flux and different gas velocity (see Fig. 13), solid downflow of solids close to the walls is more pronounced for the smaller gas velocity.

To study the impact of particle sphericity on riser radial flow, a comparison of the radial net solid flux profiles of sand and glass beads at $60 \mathrm{~kg} / \mathrm{m}^{2} \mathrm{~s}$ and gas velocity of $10 \mathrm{~m} / \mathrm{s}$ is made on Fig. 14. It can be seen that sand presents higher solid flux moving upwards in the center and moving downwards at the walls. A smaller amount of solids moving downwards and a slightly smaller annulus region would be coherent with the smaller pressure drop profiles presented by glass beads.

As discussed before, on the axial pressure drop profiles, sphericity seems to have an important and unexpected impact on solid flow inside the riser.

\section{CFD modeling}

\subsection{Barracuda}

Barracuda ${ }^{\circledR}$ is a hybrid Eulerian-Lagrangian model developed by Computational Particle Fluid Dynamic's (CPFD's). The gas is described as a continuous phase in the Eulerian description, where the Reynolds Averaged Navier Stokes equations (RANS) are used. The Lagrangian description of the solids considers it as a disperse phase where the equations for each particle will be solved using Newtonian equations [27]. The energy of the two phase mixture is conserved by exchange terms in the gas phase mass, momentum and energy equations [28].

Barracuda uses a multiphase particle-in-cell approach to decrease calculation time [29,30]. This approach consists in representing a large number of real particles by a smaller number of computational particles. It is in this computational particles that the mass and momentum conservation laws are calculated. 
The volume averaged mass and momentum equations, that describe the continuous fluid phase are shown below [30].

$$
\begin{aligned}
& \frac{\partial\left(\varepsilon \rho_{g}\right.}{\partial t}+\nabla\left(\varepsilon \rho_{g} u_{g}\right)=0 \\
& \frac{\partial\left(\begin{array}{ll}
\varepsilon & \rho_{g} u_{g}
\end{array}\right)}{\partial t}+\nabla\left(\begin{array}{ll}
\varepsilon & \rho_{g} u_{g} u_{g}
\end{array}\right)=-\nabla \mathrm{p}-\mathrm{F}+\varepsilon \quad \rho_{g} g+\nabla\left(\begin{array}{ll}
\varepsilon & \tau_{g}
\end{array}\right)
\end{aligned}
$$

The rate of momentum transfer per unit volume between the fluid and the particle phases (F) is defined as:

$$
F=\iint f m\left(F_{t}\left(u_{g}-u_{s}\right)-\frac{1}{\rho_{s}} \nabla p\right) d m d v
$$

The Lagrangian method is used to model the particles. This method considers a control volume in which the velocity of the control volume surface equals the local fluid velocity. The numerical particles in Barracuda contain a number of real particles with identical properties located at a certain known position. Particle acceleration is defined on equation 5.

$$
\frac{d u_{s}}{d t}=F_{t}\left(u_{g}-u_{s}\right)-\frac{1}{\rho_{s}} \nabla p+g-\frac{1}{(1-\varepsilon) \rho_{s}} \nabla \tau_{p}
$$

Solids movement is given by the displacement equation shown on equation 6 .

$$
\frac{d x_{s}}{d t}=u_{s}
$$

Particle properties are mapped from the particles to the Eulerian grid to obtain grid-based properties such as the particle volume fraction at cell $i$.

$$
\varepsilon_{s i}=\frac{1}{V_{i}} \sum_{1}^{N_{p}} V_{s} n_{p} S_{p i}
$$

And at cell $i$, the interphase momentum transfer is defined as:

$$
F_{i}^{n+1}=\frac{1}{\Omega_{i}} \sum_{p} S_{i}\left[F_{t}\left(u_{g, s}^{n+1}-u_{s}^{n+1}\right)-\frac{1}{\rho_{s}} \nabla p_{p}^{n+1}\right] n_{p} N_{p}
$$


A numerical particle in Barracuda contains a number of real particles that can be adjusted. Therefore, the "number density" used in Barracuda can be described as the total number of real particles in the feed divided by the number of real particles per numerical particle and by solid hold up.

In Barracuda, a series of drag force correlations can be used to determine the force acting on a particle by the fluid. The drag function chosen for the glass beads simulations conducted in this work is the Wen-Yu and Ergun correlations. Because the Wen-Yu correlation is more adapted for more dilute flows and the Ergun correlation is better for higher solids concentration flows, this is an appropriate choice for modeling the riser [30,31].

The equations used to determine drag force as a function of solids concentration are detailed below.

$$
\begin{aligned}
& F_{t}=C_{d-W \& Y} \frac{3}{8} \frac{\rho_{g}}{\rho_{s}} \frac{\left|u_{g}-u_{s}\right|}{r_{p}} \quad \varepsilon_{s}<0.75 \varepsilon_{m f} \\
& F_{t}=\frac{\varepsilon_{s}-0.75 \varepsilon_{m f}}{0.85 \varepsilon_{m f}-0.75 \varepsilon_{m f}}\left(F_{t-\text { Ergun }}-F_{t-\text { Wen\&Yu }}\right)+F_{t-W e n \& Y u} \\
& 0.75 \varepsilon_{m f}<\varepsilon_{s}<0.85 \varepsilon_{m f}
\end{aligned}
$$

Where the Wen \& Yu drag force coefficient is defined by,

$$
C_{d-W \& Y}=\left\{\begin{array}{cc}
\frac{24}{R e} \varepsilon^{-2.65} & R e<0.5 \\
\frac{24}{R e} \varepsilon^{-2.65}\left(1+0.15 R e^{0.687}\right) & 0.5 \leq R e \leq 1000 \\
0.44 \cdot \varepsilon^{-2.65} & R e>1000
\end{array}\right.
$$

The range of use of each equation is relative to the close packing solid concentration. A transition (equation 9) was developed to prevent numerical problems on the transition phase.

To simulate sand particles, that present smaller sphericity than one, the non-spherical HaiderLevenspiel model in Barracuda was used. The drag force on a particle is calculated by the following expression.

$$
F_{t}=C_{d} \frac{3}{8} \frac{\rho_{g}}{\rho_{s}} \frac{\left|u_{g}-u_{s}\right|}{r_{p}}
$$


The drag force coefficient takes into account particle sphericity $(\phi)$ as seen on equation 14 .

$$
\begin{aligned}
C_{d}=\varepsilon^{-2.65} & {\left[\frac{24}{R e}\left[1+8.1716 e^{-4.0655 \phi} R e^{(0.0964+0.5565 \phi)}\right]+\right.} \\
& \left.+\frac{73.69 e^{-5.0748 \phi} R e}{R e+5.378 e^{6.2122 \phi}}\right]
\end{aligned}
$$

In Barracuda, solids are defined as part of a "Particle Species". Each "Particle Specie" is defined by the material, particle density, particle size and particle sphericity. In this work no kinetics were studied inside the riser. Therefore, particle material is of no importance for simulation results. The "Particle Specie” size is defined by the real particle size distribution function for each solid studied.

\subsection{Geometry}

To simulate the hydrodynamics inside the riser with Group B solids, a simplified version of the experimental riser was used. The riser geometry used in Barracuda simulations does not include the blind-T exit. Therefore, comparison to experimental results will be made in the acceleration and developed regions only. The riser bottom is defined with the central air jet as shown on Fig. 15.

The small fluidization ring on the bottom of the real riser was not included in the numerical geometry. However, to simulate fluidization on the bottom, air injection points were created where the ring should be.

Riser geometry was created with CATIA ${ }^{\circledR}$ software, a 3D CAD program. Fig. 16 shows the CAD file (a), a zoomed view of the riser bottom (b) and a transparent image of the riser bottom (c). A grid can be generated automatically from an initial set of major grid lines over the geometry input. Then, the initial grid was adjusted to the riser geometry. For Barracuda it is very important to create a grid as uniform as possible with very small differences between neighboring cells. From the adjusted grid, Barracuda generated the mesh over the riser geometry.

In Barracuda two numbers of cells are displayed. The total number of cells includes all cells created in the grid, independently of the input geometry. The real number of cells are the ones created within the input geometry that will be part of the fluid domain. Therefore, the total number of cells displayed includes the real number of cells and the number of null cells, that are outside the fluid domain. The mesh system shown above has generated 186760 real and null cells. The cells inside the riser are cubes with sides of $0.03 \mathrm{~m}$.

To simplify the simulation case, it was chosen not to describe the reactor top exit. The goal was only to evaluate the capability of the code to simulate a riser with Group B particles. Because geometry is simple, no mesh related problems were encountered. 
The "number density" controls the rate at which computational particles are fed through the boundary, by increasing it the number of clouds per mesh cell will increase. Simulations were run with an initial "number density" of 200, which was increased to 700 in some simulations in an attempt to improve the match between the inlet and the outlet solid flux. The total number of particles was about $9.1 \times 10^{9}$ and the number of numerical particles, or clouds, of about $1.7 \times 10^{6}$. A study on the effect of the number density was not made in this work, the values used were chosen so the mass balance would of the riser would match.

\subsection{Boundary and initial conditions}

Boundary conditions allow for the definition and control of the entries and exits of the 3D mesh. The user chooses the location of the boundary conditions to define whether a discontinuity on the geometry wall is a flow inlet or outlet. There are also used to impose pressure, solid or gas flow rate.

The riser geometry used in all simulations has three boundary conditions, as shown on Fig. 17. The riser top, without exit geometry, is defined as flow outlet and pressure condition is imposed at the top of the riser. The top of the inlet air jet is defined as a gas entry where the gas flow rate is imposed. And the angled solids feed line is defined as solid and gas entry.

The state of the riser, gas and solids at the start of the simulations (initial conditions) will determine how long the system will take until reaching steady state. In order to decrease simulation time, at the initial condition the riser bottom is full of particles close to minimum fluidization solid concentration (0.5), as shown on Fig. 18.

The inlet air jet is defined as full gas flow rate as initial condition.

Before starting Barracuda simulations, it is known in advance the information needed to compare to experimental results available. Therefore, a series of points are set along the riser to obtain local information about pressure, particle velocity and solids concentration, called transient data points. Ten points are set along the riser axis to determine the axial pressure profile of the riser. And ten points are set over the diameter of the riser at $12 \mathrm{~m}$ high to determine radial particle concentration and velocity. The information collected on the transient data points can be averaged over time since calculation convergence is reached and then be used to compare experimental and simulation results.

The time step of simulations varied between $5 \times 10^{-4}$ and $1 \times 10^{-2}$ s, auto-adjusted by Barracuda.

\subsection{Glass beads simulations}

Glass beads flow inside the riser were simulated with the Wen-Yu/Ergun drag force correlation for 200 seconds. The operating conditions were chosen to match an experimental case for glass beads. The simulation was done at gas velocity of $10 \mathrm{~m} / \mathrm{s}$, solid flux $60 \mathrm{~kg} / \mathrm{m}^{2} \mathrm{~s}$ and a top pressure of $109000 \mathrm{~Pa}$. The evolution of pressure drop with simulation time along the riser is presented on Fig. 19. 
It can be seen that it takes about $75 \mathrm{~s}$ (average between 65 to $85 \mathrm{~s}$ ) to approach the final pressure drop profile. However, until $150 \mathrm{~s}$ (average between 140 to $160 \mathrm{~s}$ ) higher pressure drop on the first $5 \mathrm{~m}$ can be seen, indicating a flow not yet fully developed. With time solid concentration stabilizes along the riser. After $150 \mathrm{~s}$, steady state condition is assumed and pressure drop data was therefore averaged over the period 150-200 s to compare with experimental results. To verify simulation convergence, the inlet and outlet solid fluxes were also compared to ensure there is no mass balance changes.

Fig. 20 shows the pressure profile of the riser (as a line) resulting from the Barracuda simulation and averaged over the last $50 \mathrm{~s}$ (dotted line on Fig. 19).

As stated before, Barracuda has as an entry point, the pressure at the top of the riser. The pressure at the top is imposed by the respective boundary condition. This pressure value can only be estimated from the experimental results because the value is influenced by the exit geometry. As the riser geometry in Barracuda does not have the blind T exit, pressure drop at the top should be lower.

The pressure at the top of the riser assigned for the simulation was slightly too small. Direct correction of the results to match pressure at $12 \mathrm{~m}$ was made. The pressure outlet adjustment is minor $(1.2 \mathrm{kPa})$ and the impact on simulations should be negligible.

It can be seen from Fig. 20 that the experimental pressure profiles obtained with glass beads is very close to the one obtained from the Barracuda simulation at identical conditions.

Barracuda is able to correctly predict the slope of the first meter of the riser and the different slope of the accelerated zone. The CFD code is able to simulate the acceleration zone at the bottom of the riser as the experimental pressure profiles showed. The evidence of the bottom region with higher solids concentration can also be seen on Fig. 21. The solids concentration mapping shows the solids inlet and the lower riser region where solid concentration can be very high due to particle acceleration.

A second glass beads simulation was made with the Wen-Yu/Ergun drag force correlation for 200 seconds. The simulation was done at gas velocity of $8 \mathrm{~m} / \mathrm{s}$, solid flux $54 \mathrm{~kg} / \mathrm{m}^{2} \mathrm{~s}$ and a top pressure of 106821 Pa. Fig. 22 shows the experimental pressure profile at identical conditions (pressure adjusted) as well as the Barracuda simulation.

The commercial CFD code is able to predict the bottom zone acceleration responsible for a great part of the total pressure drop. The difference in pressure drop (between 0.15 and $11 \mathrm{~m}$ ) between the experimental profile and Barracuda is of $2 \%$.

Local vertical solid velocities over the riser diameter at $12 \mathrm{~m}$ from the gas inlet are shown on Fig. 23. The radial solids velocity profile shows the high gradient existing between the center of the riser (at radial position of $0.15 \mathrm{~m}$ ) and the riser walls. At the center of the riser particles travel at a faster velocity, approaching the gas velocity. Yet, close to the riser walls, vertical velocity is much smaller. The profile suggests the existence of a core-annulus regime, where the particles travel upwards in the center. However, the Barracuda simulation does not predict a time- averaged downward solid flow close to the wall like it was shown on experimental results, by local flux measurements.

The radial profile of local voidage values at $12 \mathrm{~m}$ from the gas inlet is shown on Fig. 23. 
It can be seen how the solids volume fraction is higher closer to the riser walls. The profiles seem slightly asymmetrical, this could be linked to average time used to calculate the profiles. Experimental results of radial solid flux have shown rather symmetrical radial profiles. This result shows how Barracuda can partially predict the core-annulus regime on the developed region of the riser.

From the local results of velocity and voidage shown above, the local solid flux can be calculated through equation 15.

$$
W_{s}=u_{s} \cdot \rho_{s} \cdot \varepsilon_{s}
$$

To determine the values presented on Fig. 24, the values of solid flux were calculated for each point and then divided by the integrated value of the solid flux, $57 \mathrm{~kg} / \mathrm{m}^{2} \mathrm{~s}$.

The values of dimensionless local solid flux from the Barracuda simulation are smaller than the experimental results. Because there is experimentally downward solids flow on the wall, there has to be higher upward solid flux in the center to obtain a similar value of integrated solid flux. Considering that Barracuda does not predict averaged downward solid flow at the wall, a flat profile, like the one shown on Fig. 24, would be expected. The difficulty on predicting a correct core-annulus flow in the riser may partially come from the lack of cluster formation and interaction. Yang et al. [32] revealed CFD simulations where the core-annulus regime was found in a 2D, $10 \mathrm{~m}$ riser with fine particles (54 $\mu \mathrm{m})$. However, negative solid velocities were found only at $3.5 \mathrm{~m}$ high. At $8.75 \mathrm{~m}$, velocity and voidage profiles became much flatter, like in this work. The author recognizes that the difficulty in simulating cluster formation impacts CFD results.

One could also argue that the absence of blind-T exit in the simulations may impact the riser flow as well. However, based on experimental pressure profiles, results suggest that riser exit effect does not affect the flow structure in the first $13 \mathrm{~m}$. Therefore, the lack of blind-T is not enough to explain differences observed between experimental and simulated profiles.

\subsection{Sand simulations}

The flow of sand particles inside the riser were simulated with the Haider \& Levenspiel drag force correlation for 170 seconds. Steady state was reached after around $100 \mathrm{~s}$. The simulation was done at gas velocity of $10 \mathrm{~m} / \mathrm{s}$, solid flux $60 \mathrm{~kg} / \mathrm{m}^{2} \mathrm{~s}$ and a top pressure of $113000 \mathrm{~Pa}$. Fig. 25 shows the comparison between the Barracuda simulation and the corresponding experimental results.

It can be seen that Barracuda cannot predict the pressure drop generated by the non-spherical particles. The acceleration zone may present a correct slope initially compared to the experimental results, butacceleration length is clearly under predicted. Barracuda generates a shorter dense bottom region and therefore, smaller pressure drop in this zone. 
In the developed region, Barracuda predicts an overall smaller pressure drop than the experimental results. It can be seen from the smaller slope of the Barracuda pressure profiles that the impact of the particle sphericity seems to be underpredicted by the CFD code.

The difference in pressure drop (between 0.15 and $11 \mathrm{~m}$ ) between the experimental profile and Barracuda simulation is of $43 \%$. The conclusion made from the glass beads simulations, that the coreannulus regime is only partially predicted may also be a reason for the poor performance of Barracuda with sand particles. It was seen experimentally that the annulus region of sand flow is bigger than for glass beads and should account for a great portion of the pressure drop along the riser. If Barracuda cannot correctly predict the core-annulus regime in the riser then the pressure drop will be systematically underpredicted.

\section{Conclusion}

Experimental tests were conducted with two different Group B particles on a large scale CFB to study the impact of particle shape on riser hydrodynamic. Simulations at identical conditions were then conducted using a commercial CFD code, Barracuda.

For identical operating conditions, sand and glass beads experimental axial pressure drop profiles show a difference of approximately 50\%. Pressure drops for glass beads, with sphericity of 1 , are consistently smaller than those of sand, with sphericity of 0.83 . The results, for a wide range of operating conditions, suggest a substantial impact of particle shape on the flow inside the riser. Such impact could also be detected on radial solid flux profiles. In the developed region, the flow can be characterized by a core-annulus structure. Particle sphericity seems to impact the structure of the coreannulus regime, suggesting that lower sphericity results in larger annulus region. Differences seen on the axial pressure profiles of sand and glass beads would be explained in part by the larger annulus region.

Barracuda has been shown to predict quite well the pressure drop profiles of glass beads. The Wen \& $\mathrm{Yu} /$ Ergun drag force correlation for spherical particles is capable of simulating glass beads pressure profiles along the riser.

However, the CFD code has not been able to accurately predict pressure profiles for sand particles. The use of the Haider and Levenspiel model for non-spherical particles seems to underestimate the pressure drop generated by particles with sphericity of 0.83 .

The core annulus regime is partially predicted by Barracuda, with significant deformation of radial particle velocity and voidage profiles. However, the downward solids flow at the wall seems underpredicted and the radial solid flux profiles are quite flat. This result could be the effect of several parameters, like the drag force correlations used but also from mesh impact.

In the present work, standard drag correlations and CFD simulation parameters were used. Based on the discrepancy between experimental results and simulations, more detailed investigations should be 
conducted in order to evaluate, for instance, the impact of alternative drag correlations and select more appropriate closure equations. 
Notation

$C_{d} \quad$ Drag coefficient

$d_{p} \quad$ Particle diameter (m)

$F_{t} \quad$ Drag force $\left(\mathrm{N} / \mathrm{m}^{3}\right)$

$h \quad$ Height (m)

$n_{p} \quad$ Number of particles in a numerical particle

$N_{p} \quad$ Number of numerical particles

$\triangle P \quad$ Pressure drop $(\mathrm{Pa})$

Re Reynolds number

$S \quad$ Interpolation operator

$t \quad$ Time (s)

$u_{g} \quad$ Superficial gas velocity $(\mathrm{m} / \mathrm{s})$

$u_{s} \quad$ Solid velocity $(\mathrm{m} / \mathrm{s})$

$W_{s} \quad$ Solid flux $\left(\mathrm{kg} / \mathrm{m}^{2} \mathrm{~s}\right)$

$x_{s} \quad$ Solid position

$\varepsilon \quad$ Voidage

$\varepsilon_{m f} \quad$ Voidage at minimum fluidization velocity

$\mu_{g} \quad$ Viscosity (cP)

$\rho_{g} \quad$ Gas density $\left(\mathrm{kg} / \mathrm{m}^{3}\right)$

$\rho_{s} \quad$ Solid density $\left(\mathrm{kg} / \mathrm{m}^{3}\right)$

$\tau_{g} \quad$ Fluid stress tensor 
[1] Yazdanpanah, M. M. Investigation of a Chemical Looping Combustion (CLC) Configuration with Gas Feed. 2011. Université Henri Poincaré, Nancy 1 (EMMA).

Ref Type: Thesis/Dissertation

[2] M. M. Hossain and H. I. de Lasa, Chemical-looping combustion (CLC) for inherent separation - a review, Chemical Engineering Science, 63 (2008) 4433-4451.

[3] J. Adánez, A. Abad, F. Garcia-Labiano, P. Gayan, and L. F. de Diego, Progress in Chemical-Looping Combustion and Reforming technologies, Progress in Energy and Combustion Science, 38 (2012) 215-282.

[4] M. M. Yazdanpanah, A. Forret, T. Gauthier, and A. Delebarre, An experimental investigation of L-valve operation in an interconnected circulating fluidized bed system, Powder Technology, 221 (2012) 236-244.

[5] S. Bourgeon, T. Gauthier, F. Guillou, and H. Stainton, Chemical Looping Combustion: Development status and perspectives, CLC 2012, Darmstadt, Germany, (2012).

[6] Y. L. Yang, Y. Jin, Z. Q. Yu, and Z. W. Wang, Investigation on slip velocity distributions in the riser of dilute circulating fluidized bed, Powder Technology, 73 (1992) 67-73.

[7] A. Yan, J. Ball, and J. Zhu, Scale-up effect of riser reactors (3) axial and radial solids flux distribution and flow development, Chemical Engineering Journal, 109 (2005) 97106.

[8] J. W. Chew, R. Hays, J. G. Findlay, T. M. Knowlton, S. B. R. Karri, R. A. Cocco, and C. M. Hrenya, Cluster characteristics of Geldart Group B particles in a pilot-scale CFB riser. I. Monodisperse systems, Chemical Engineering Science, 68 (2012) 72-81.

[9] J. W. Chew, R. Hays, J. G. Findlay, T. M. Knowlton, S. B. R. Karri, R. A. Cocco, and C. M. Hrenya, Reverse core-annular flow of Geldart Group B particles in risers, Powder Technology, (2012).

[10] Rodrigues, S. S. Flow modeling of Group B particles in the transport regime for CLC. 2014.

Ref Type: Thesis/Dissertation

[11] S. S. Rodrigues, A. Forret, F. Montjovet, M. Lance, and T. Gauthier, Riser hydrodynamic study with different Group B powders, Powder Technology, 272 (2015) 300-308.

[12] B. Herb, S. Dou, K. Tuzla, and J. C. Chen, Solid mass fluxes in circulating fluidized beds, Powder Technology, 70 (1992) 197-205.

[13] W. Zhang, F. Johnsson, and B. Leckner, Momentum probe and sampling probe for measurement of particle flow properties in CFB boilers, Chemical Engineering Science, 52 (1997) 497-509.

[14] R. Bader, J. Findlay, and T. M. Knowlton, Gas solid flow patterns in a $30.5 \mathrm{~cm}$ diameter circulating fluidized bed, Circulating Fluidized Bed Conf., (1988).

[15] M. Kruse and J. Werther, 2D gas and solids flow prediction in circulating fluidized beds based on suction probe and pressure profile measurements, Chemical Engineering and Processing: Process Intensification, 34 (1995) 185-203.

[16] D. Geldart, Types of gas fluidization, Powder Technology, 7 (1973) 285-292.

[17] D. Kunii and O. Levenspiel, Fluidization Engineering, Butterworth-Heinmann, 1991.

[18] S. Tran-Cong, M. Gay, and E. E. Michaelides, Drag coefficients of irregularly shaped particles, Powder Technology, 139 (2004) 21-32.

[19] J. Xu and J. Zhu, Effects of particle properties on flow structure in a 2-D circulating fluidized bed: Solids concentration distribution and flow development, Chemical Engineering Science, 66 (2011) 5064-5076. 
[20] Yang W.C., Handbook of Fluidization and Fluid-Particle Systems, Marcel Dekker, Inc., 2003.

[21] Y. Zhou, J. Peng, X. Zhu, and M. Zhang, Hydrodynamics of gas-solid flow in the circulating fluidized bed reactor for dry flue gas desulfurization, Powder Technology, 205 (2011) 208-216.

[22] J. R. Grace, A. A. Avidan, and T. M. Knowlton, Circulating Fluidized Beds, Blackie Academic \& Professional, 1997.

[23] S. K. Gupta and F. Berruti, Evaluation of the gas solid suspension density in CFB risers with exit effects, Powder Technology, 108 (2000) 21-31.

[24] J. S. Kim, R. Tachino, and A. Tsutsumi, Effects of solids feeder and riser exit configuration on establishing high density circulating fluidized beds, Powder Technology, 187 (2008) 37-45.

[25] M. Rhodes, H. Mineo, and T. Hirama, Particle motion at the wall of a circulating fluidized bed, Powder Technology, 70 (1992) 207-214.

[26] S. B. R. Karri and T. M. Knowlton, A comparison of annulus solids flow direction and radial solids mass flux profiles at low and high mass fluxes in a riser, Circulating Fluidized Bed Technology VI, (1999).

[27] R. K. Gupta, V. Kumar, and V. K. Srivastava, Modeling of Fluid Catalytic Cracking Riser Reactor: A Review, International Journal of Chemical Reactor Engineering, 8 (2010).

[28] E. M. Ryan, D. DeCroix, R. Breault, W. Xu, E. D. Huckaby, K. Saha, S. Dartevelle, and X. Sun, Multi-phase CFD modeling of solid sorbent carbon capture system, Powder Technology, 242 (2013) 117-134.

[29] D. M. Snider, An Incompressible Three-Dimensional Multiphase Particle-in-Cell Model for Dense Particle Flows, Journal of Computational Physics, 170 (2001) 523-549.

[30] C. Chen, J. Werther, S. Heinrich, H. Y. Qi, and E. U. Hartge, CPFD simulation of circulating fluidized bed risers, Powder Technology, 235 (2013) 238-247.

[31] D. Gidaspow, Multiphase Flow and Fluidization: Continuum and Kinetic Theory Descriptions, Academic Press Inc., 1994.

[32] N. Yang, W. Wang, W. Ge, and J. Li, CFD simulation of concurrent-up gas-solid flow in circulating fluidized beds with structure-dependent drag coefficient, Chemical Engineering Journal, 96 (2003) 71-80. 


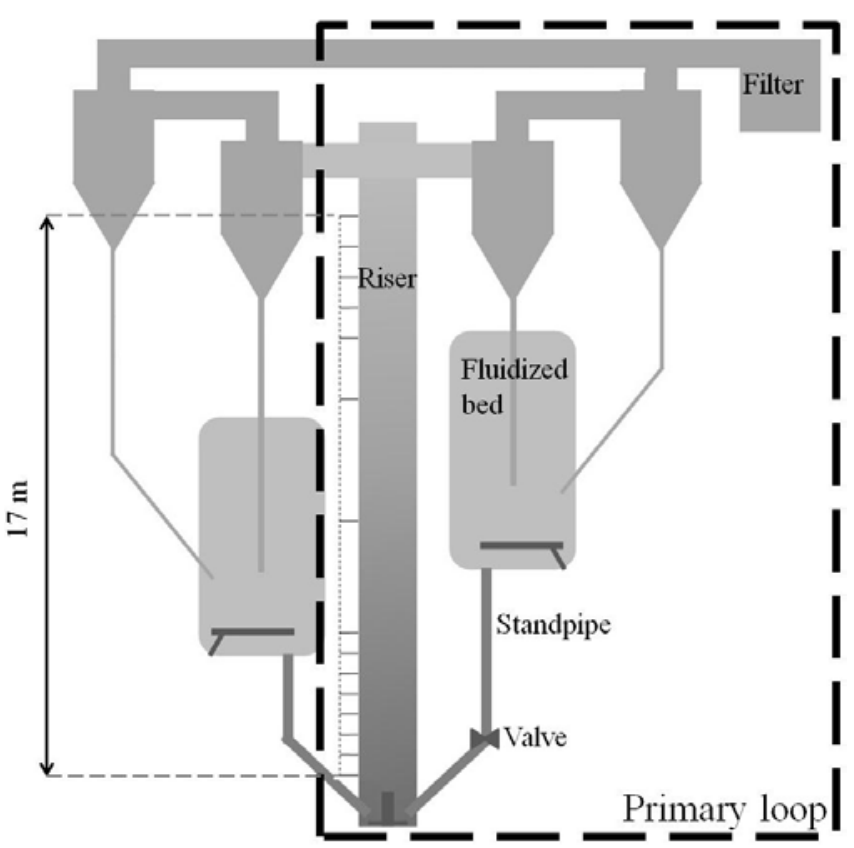

Fig. 1 - Schematic representation of the cold flow mock up used in the present work.

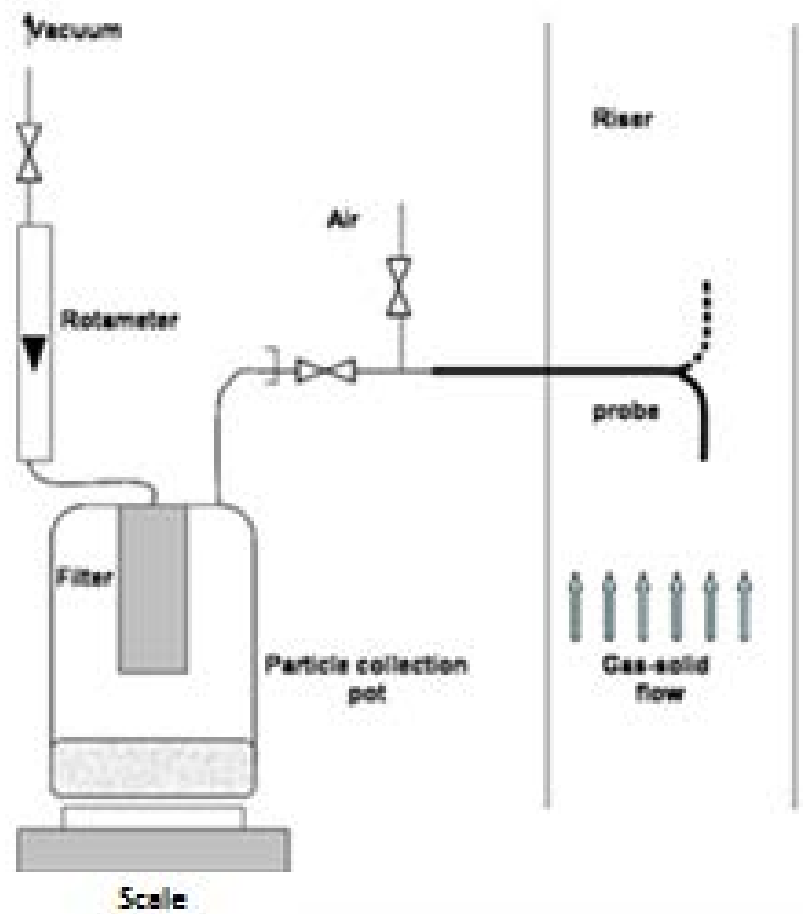

Fig. 2 - A schematic view of the extraction system collecting particles from the riser (on the right). 


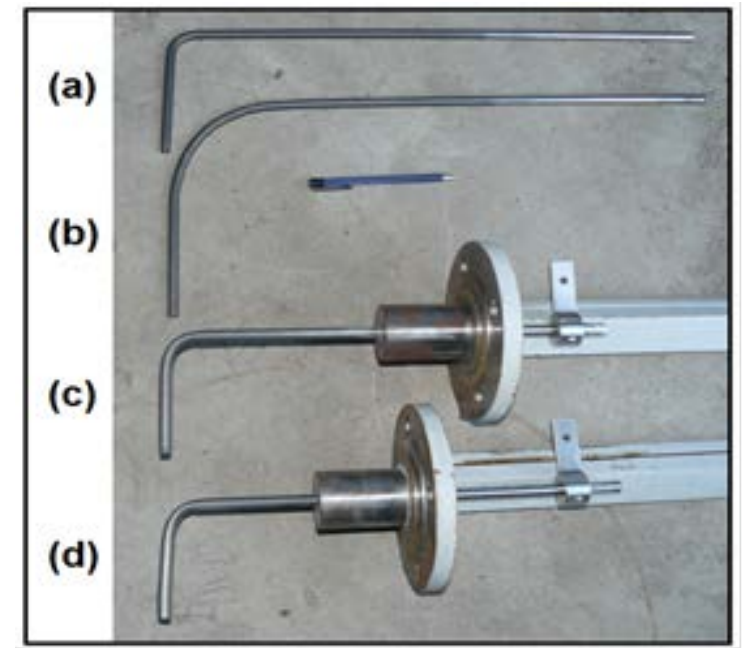

Fig. 3 - Different extraction probes tested in this work.

\section{Probe (d)}

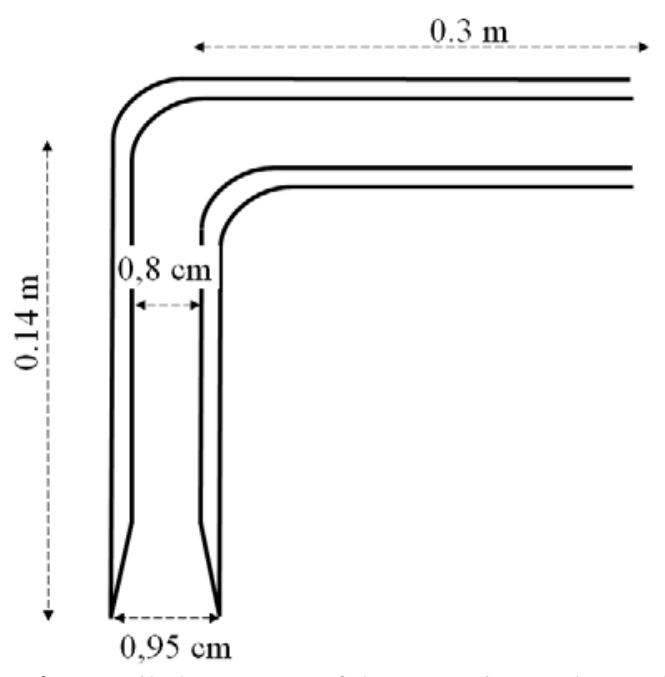

Fig. 4 - Detailed geometry of the extraction probe used in this work.

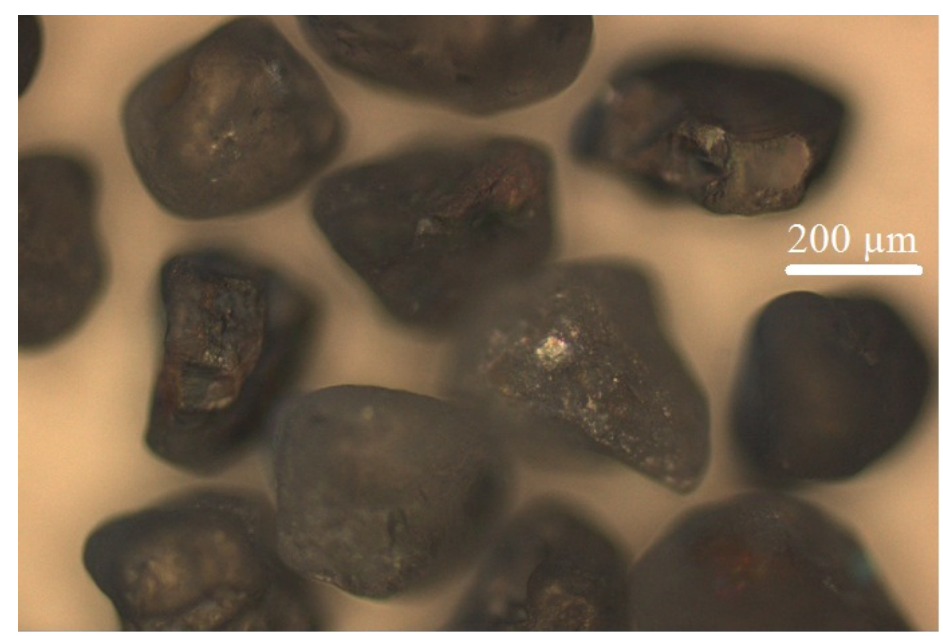

Fig. 5 - Microscopic image of sand particles. 


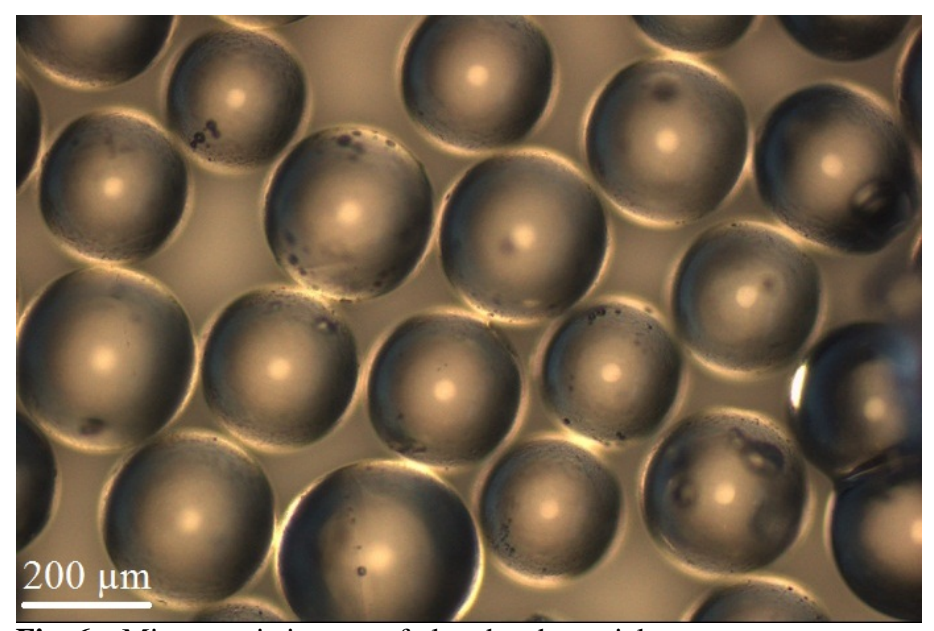

Fig. 6 - Microscopic images of glass beads particles.

Table 1 - Particle properties for sand and glass beads.

\begin{tabular}{c|c|c} 
& Sand & Glass beads \\
\hline $\begin{array}{c}\text { Final Equilibrium Sauter mean } \\
\text { diameter }(\mu \mathrm{m})\end{array}$ & 300 & 250 \\
\hline Density $\left(\mathrm{kg} / \mathrm{m}^{3}\right)$ & 2650 & 2600 \\
\hline $\begin{array}{c}\text { Experimental minimum } \\
\text { fluidization velocity }(\mathrm{cm} / \mathrm{s})\end{array}$ & 7.1 & 6.5 \\
\hline Sphericity & 0.83 & 1 \\
\hline $\begin{array}{c}\text { Terminal velocity corrected } \\
\text { with sphericity }(\mathrm{m} / \mathrm{s})\end{array}$ & 2.1 & 2.2
\end{tabular}

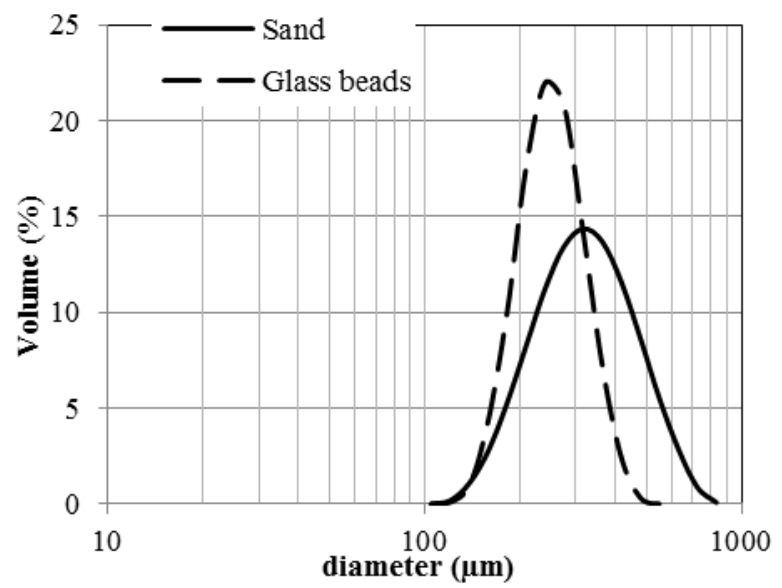

Fig. 7 - Particle size distribution at equilibrium state for sand, and glass beads. 


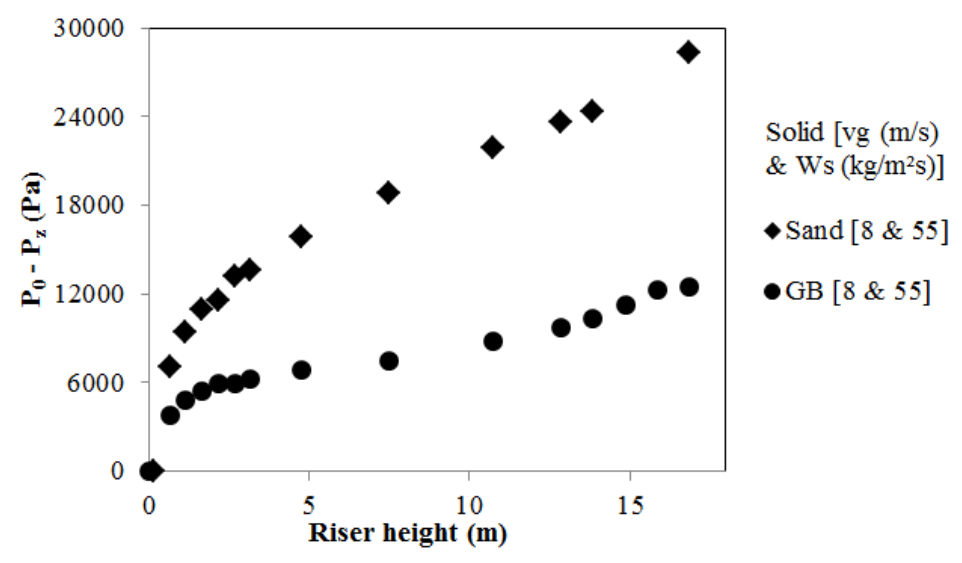

Fig. 8 - Axial pressure drop profiles for sand and glass beads at gas velocity of $8 \mathrm{~m} / \mathrm{s}$ and solid flux of $55 \mathrm{~kg} / \mathrm{m}^{2} \mathrm{~s}$.

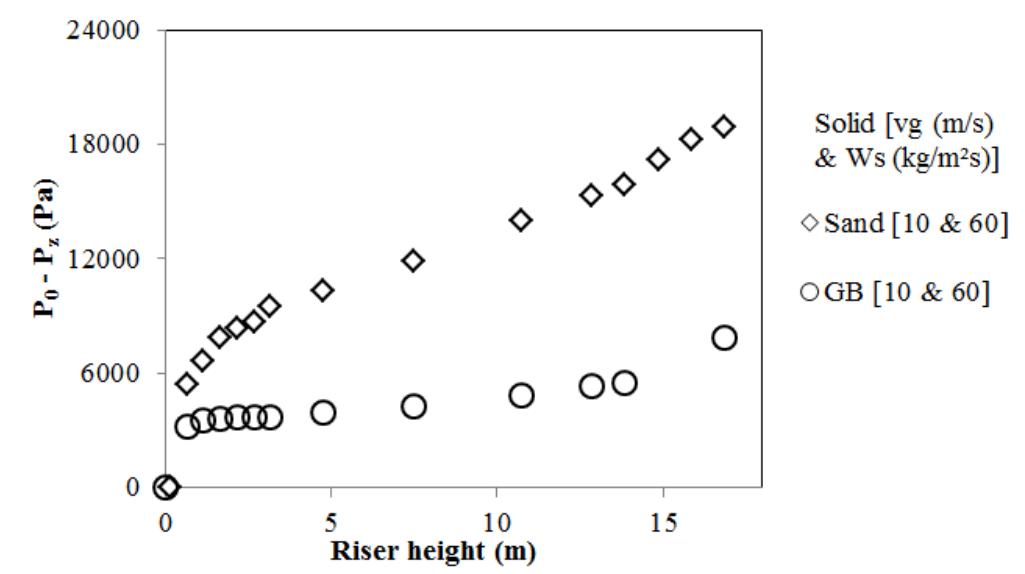

Fig. 9 - Axial pressure drop profiles for sand and glass beads at gas velocity of $10 \mathrm{~m} / \mathrm{s}$ and solid flux of $60 \mathrm{~kg} / \mathrm{m}^{2} \mathrm{~s}$.

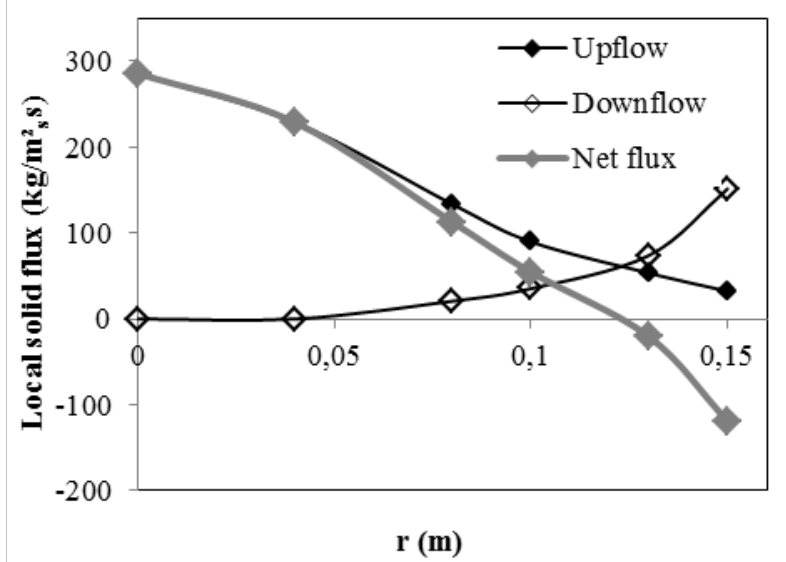

Fig. 10 - Upwards and Downwards radial solid flux profiles for sand at $10 \mathrm{~m} / \mathrm{s}$ and solid flux of $60 \mathrm{~kg} / \mathrm{m}^{2} \mathrm{~s}$. 


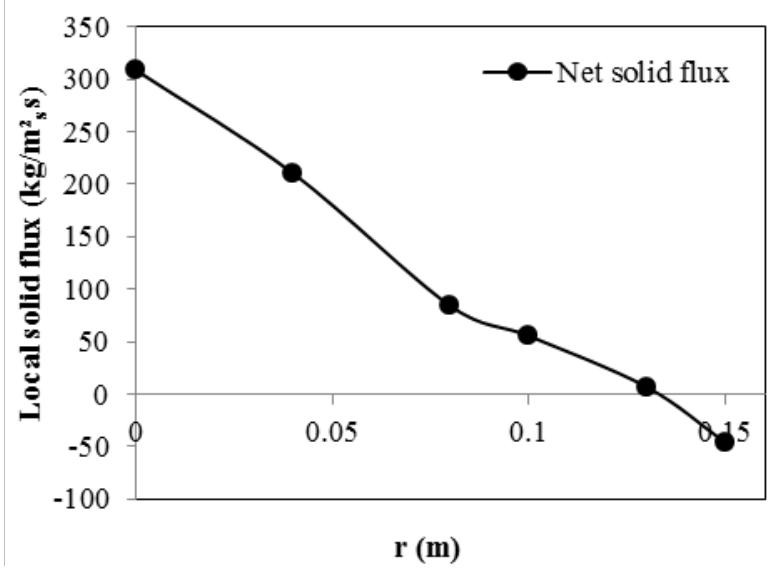

Fig. 11 - Net radial solid flux profile for glass beads at gas velocity of $10 \mathrm{~m} / \mathrm{s}$ and solid flux of $60 \mathrm{~kg} / \mathrm{m}^{2} \mathrm{~s}$.

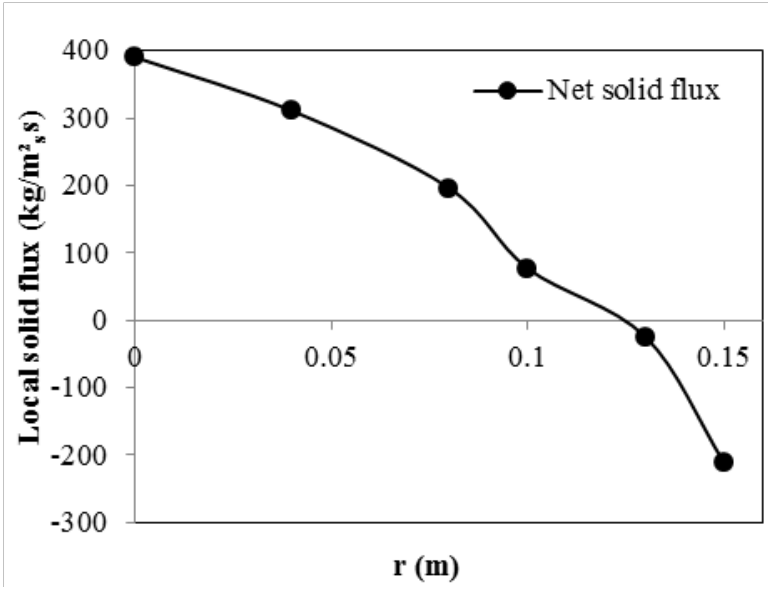

Fig. 12 - Net radial solid flux profile for glass beads at gas velocity of $8 \mathrm{~m} / \mathrm{s}$ and solid flux of $57 \mathrm{~kg} / \mathrm{m}^{2} \mathrm{~s}$.

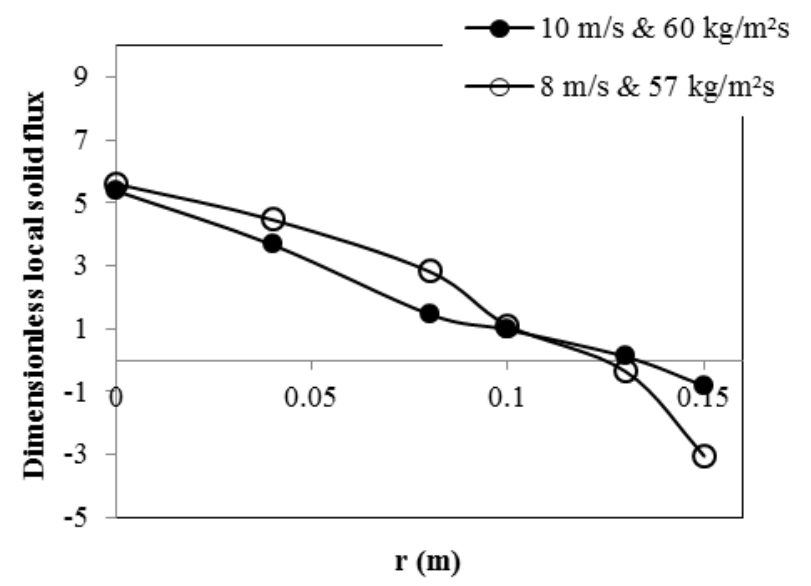

Fig. 13 - Dimensionless radial solid flux profiles of glass beads at two different conditions. 


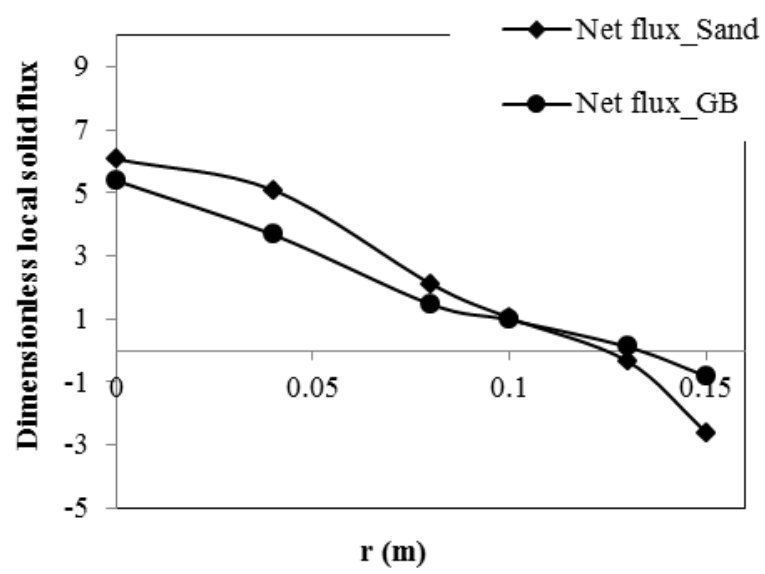

Fig. 14 - Dimensionless radial solid flux profiles of sand and glass beads at $10 \mathrm{~m} / \mathrm{s}$ and solid flux of $60 \mathrm{~kg} / \mathrm{m}^{2} \mathrm{~s}$.

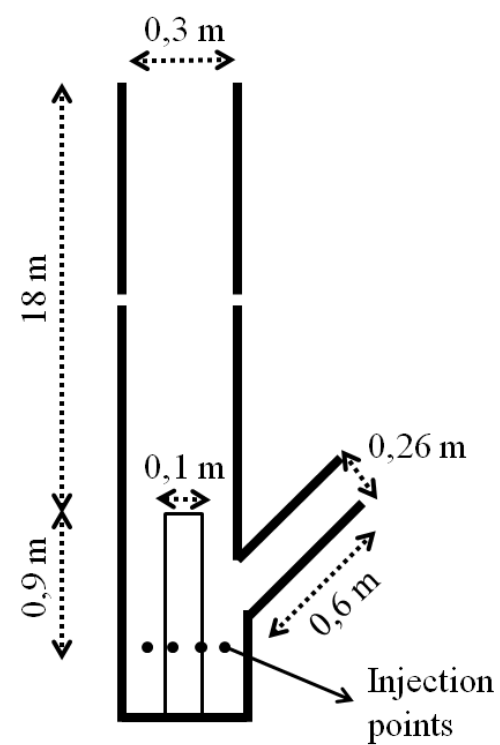

Fig. 15 - Schematic view of the riser with measurements used in Barracuda simulations. 
(a)

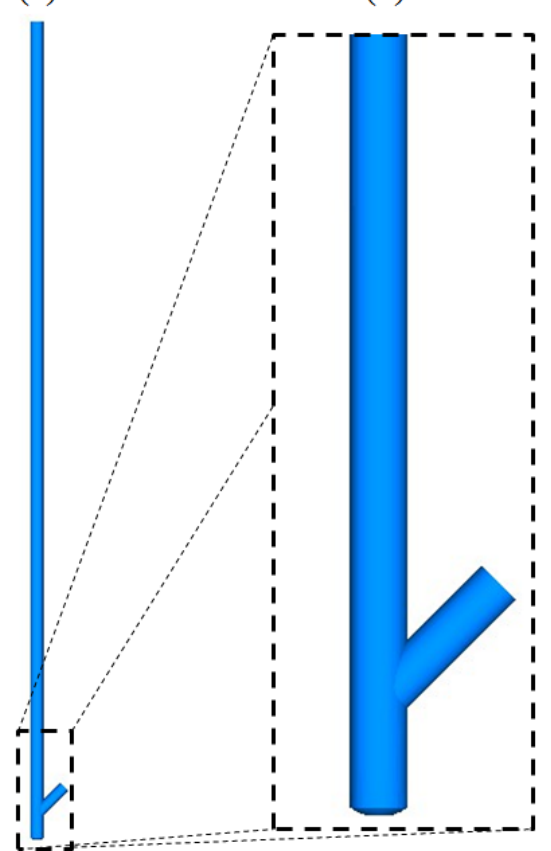

(c)

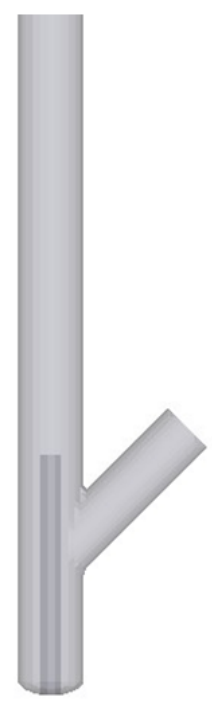

Fig. 16 - Images of the CAD file as introduced on Barracuda.

\section{Riser outlet \\ (P)}

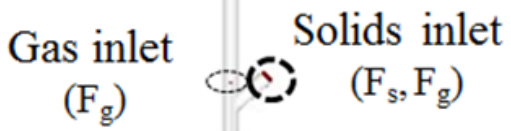

Fig. 17 - Boundary conditions for all Barracuda simulations. 


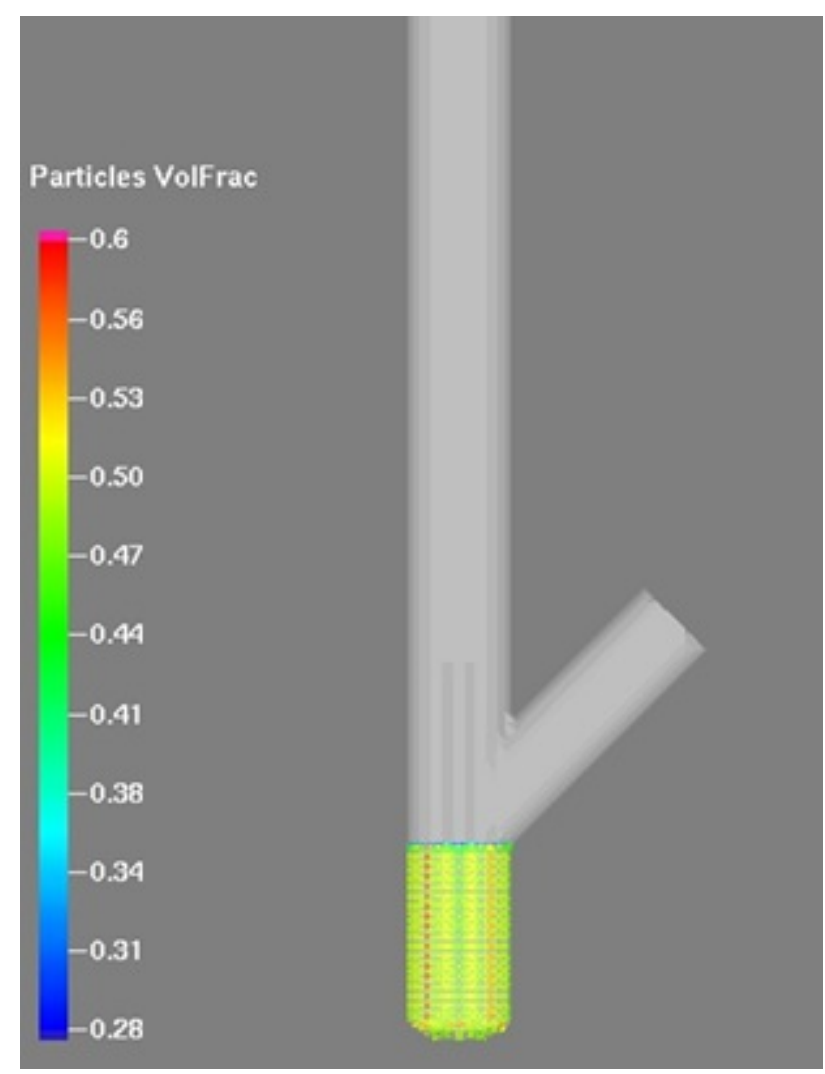

Fig. 18 - Initial solids condition for all Barracuda simulations, scale of solids concentration on left.

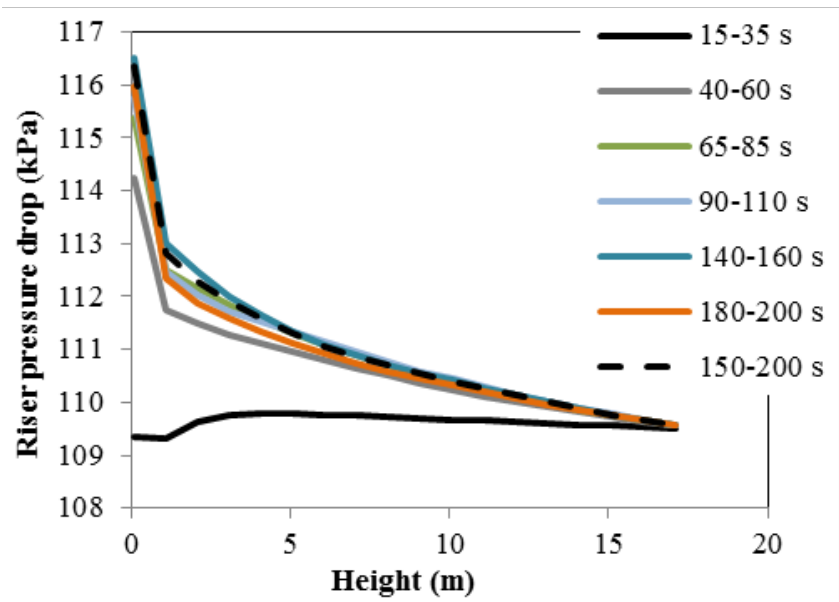

Fig. 19 - Pressure drop evolution with simulation time of glass beads. 


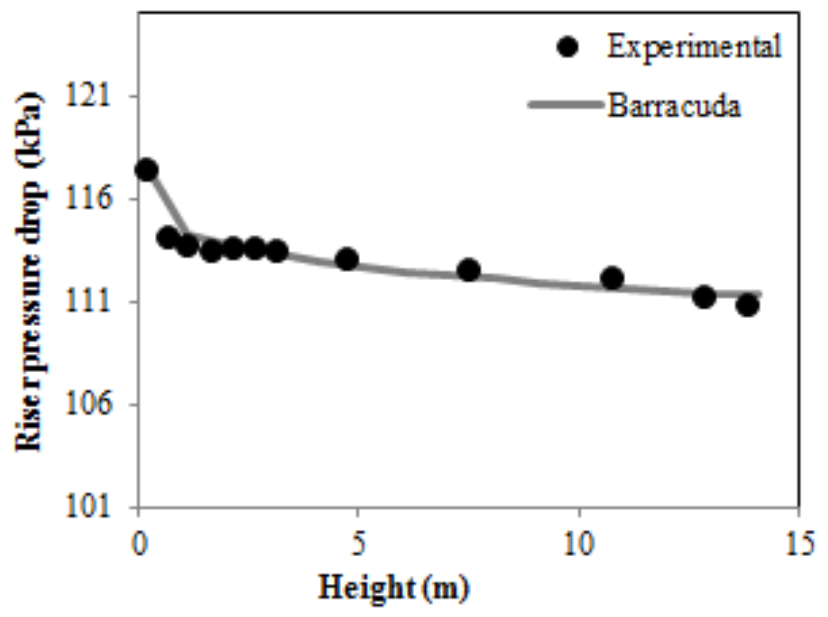

Fig. 20 - Comparison between Barracuda simulation and glass beads experimental values of pressure along the riser at gas velocity of $10 \mathrm{~m} / \mathrm{s}$ and solid flux of $60 \mathrm{~kg} / \mathrm{m}^{2} \mathrm{~s}$.

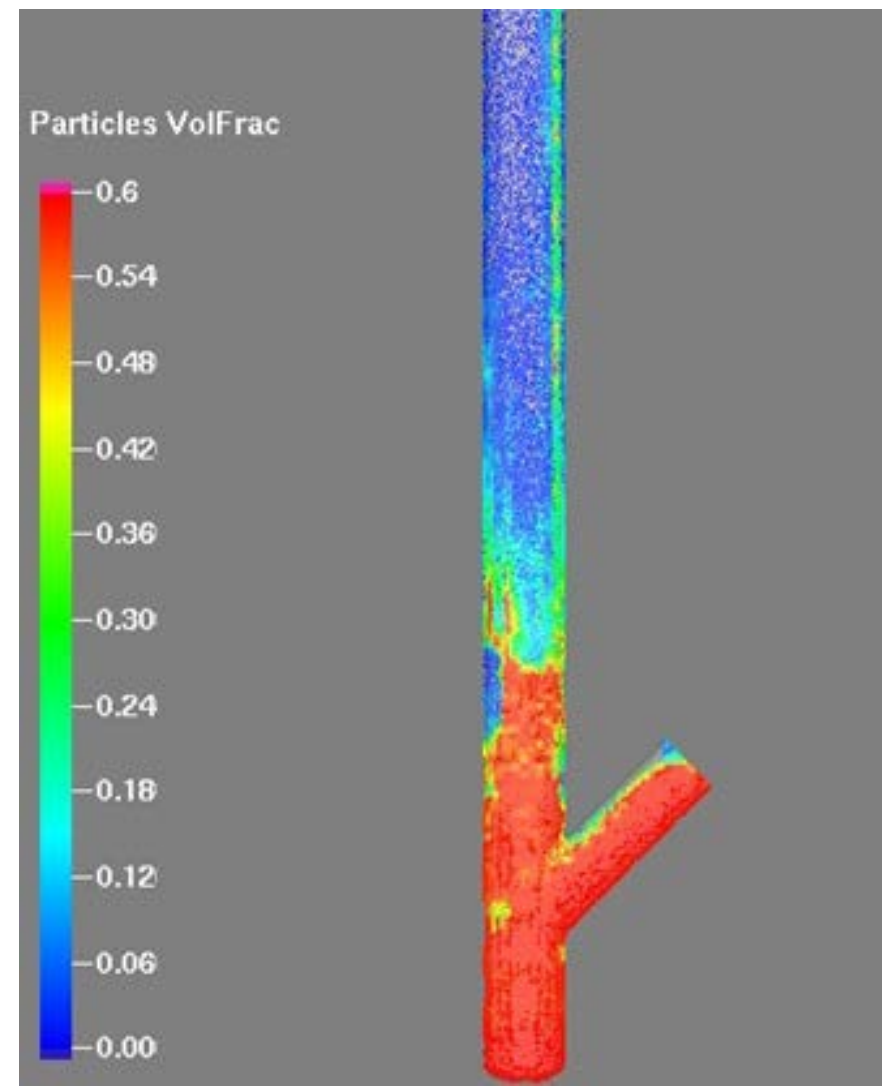

Fig. 21 - Simulation still image of solid concentration at the bottom of the riser at $200 \mathrm{~s}$. 


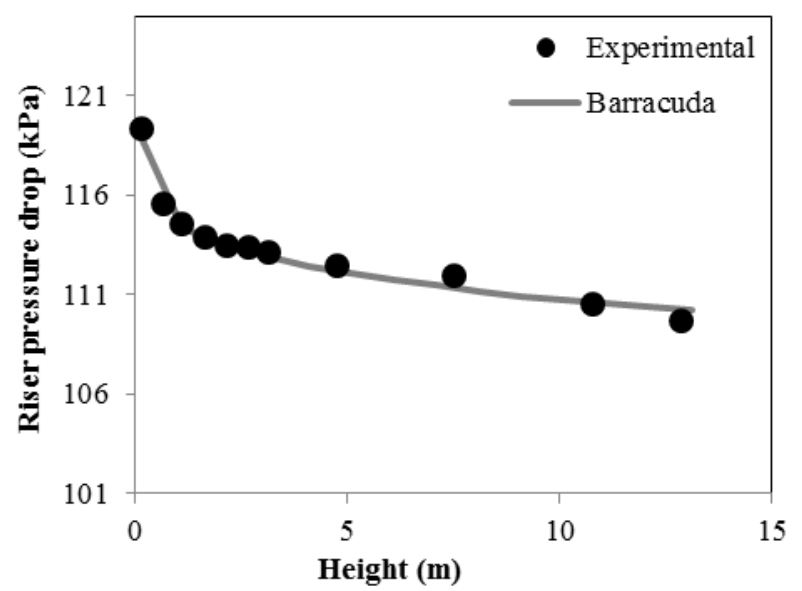

Fig. 22 - Comparison between Barracuda results and glass beads experimental values of pressure along the riser at gas velocity of $8 \mathrm{~m} / \mathrm{s}$ and solid flux of $54 \mathrm{~kg} / \mathrm{m}^{2} \mathrm{~s}$.

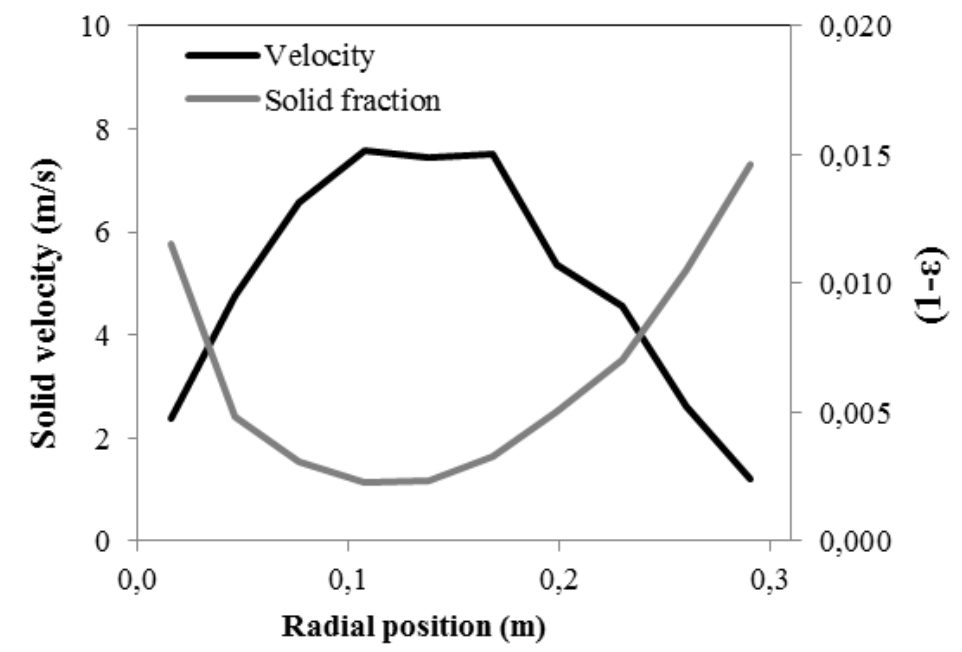

Fig. 23 - Solid velocity radial profile (left axis) and solid fraction (1-ع) radial profile (right axis) $12 \mathrm{~m}$ from the gas inlet at gas velocity of $8 \mathrm{~m} / \mathrm{s}$ and solid flux of $54 \mathrm{~kg} / \mathrm{m}^{2} \mathrm{~s}$.

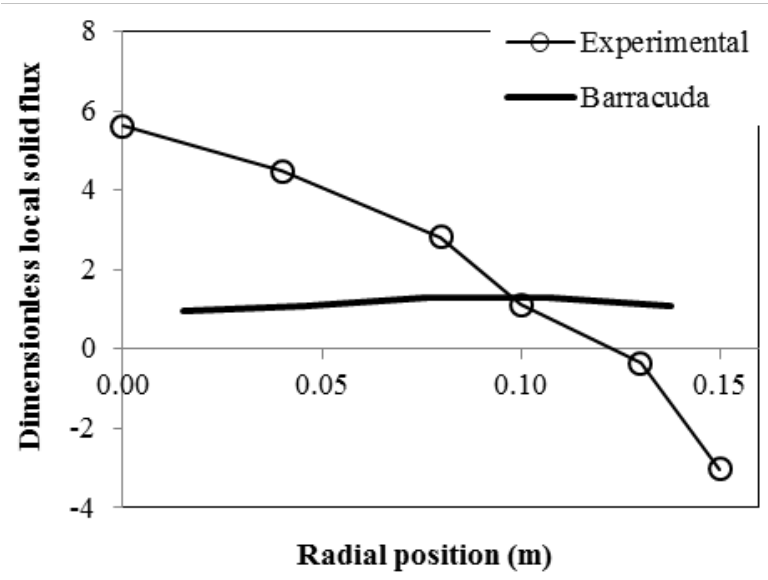

Fig. 24 - Comparison between experimental and Barracuda radial dimensionless solid flux at gas velocity of $8 \mathrm{~m} / \mathrm{s}$ and solid flux of $54 \mathrm{~kg} / \mathrm{m}^{2} \mathrm{~s}$.. 


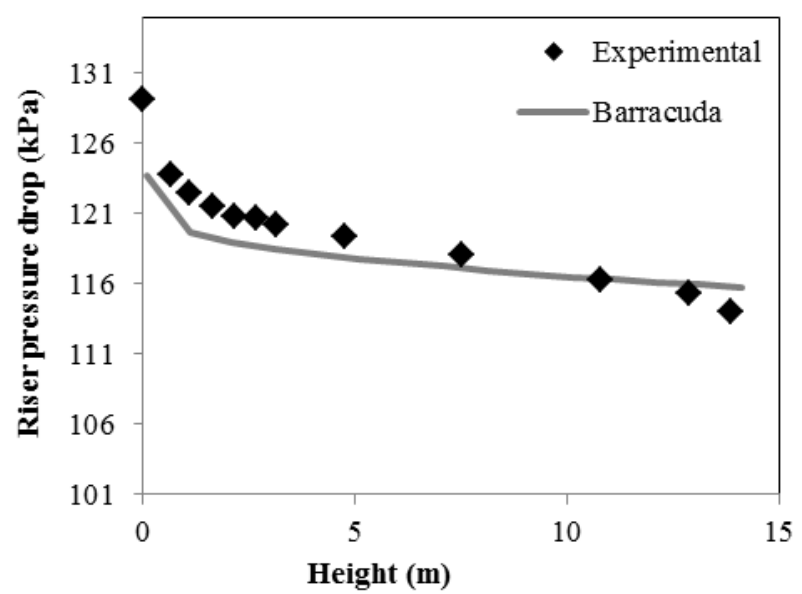

Fig. 25 - Comparison between Barracuda results and sand experimental values of pressure along the riser at gas velocity of $10 \mathrm{~m} / \mathrm{s}$ solid flux of $60 \mathrm{~kg} / \mathrm{m}^{2} \mathrm{~s}$. 